\title{
Tissue engineering and regenerative orthopaedics (TERO)
}

\author{
Marko Pećina • Slobodan Vukičević
}

Received: 18 July 2014 / Accepted: 18 July 2014 / Published online: 12 August 2014

(C) SICOT aisbl 2014

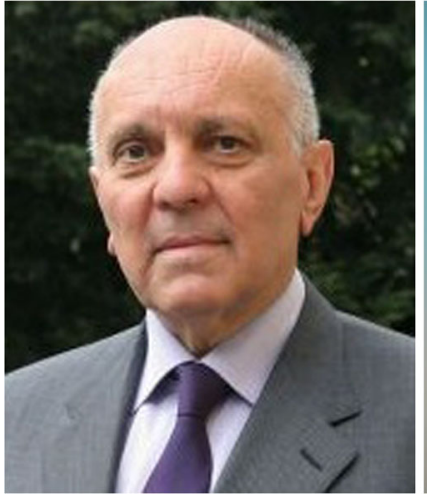

Marko Pećina

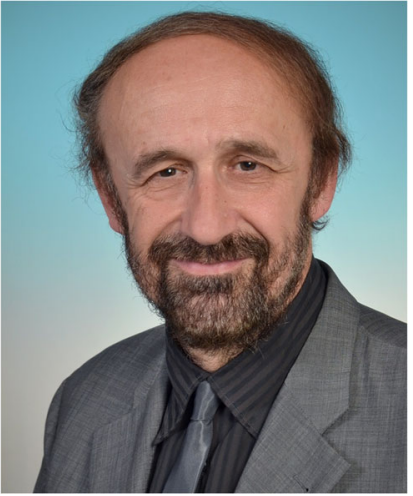

Slobodan Vukičević
According to Greek mythology, Prometheus' liver grew back nightly after it was removed each day by an eagle as punishment for giving fire to mankind. Hence, the concept of tissue and organ regeneration is not new. Combinations of the three major components of regenerative medicine: cells, biomaterials and bioactive molecules have created a new paradigm of future therapeutic options for most species. Orthopaedic injuries are a source of enhanced misery and economic burden, because tissues like cartilage, meniscus, and intra-articular ligaments do not heal. Even the bone repair, which normally occurs spontaneously, can fail. The regeneration of orthopaedic tissues requires cells, morphogenetic signals, scaffolds, and an appropriate mechanical environment. The last Special

\section{Pećina}

Department of Orthopaedic Surgery, University of Zagreb School of Medicine, Zagreb, Croatia

e-mail: marko.pecina@zg.t-com.hr

\section{S. Vukičević $(\square)$}

Laboratory for Mineralized Tissues, Centre for Translational and Clinical Research, University of Zagreb School of Medicine, Zagreb, Croatia

e-mail: vukicev@mef.hr
Issue of International Orthopaedics covering regeneration of bone, cartilage and tendon was edited by us in 2007 [1]. Since then, the field of tissue engineering and skeletal regeneration has progressed by development of novel biomaterials, devices, growth factor carriers and their use in patients.

Obstacles to the sustained delivery of individual growth factors can be addressed by gene transfer or smart scaffolds based on natural products, synthetic materials, or devitalized extracellular matrix. Traditional tissue engineering practices are costly, cumbersome, and not well suited to treating large numbers of individuals and, therefore, approaches using intrinsic biological processes in vivo avoid the need for ex vivo expansion of autologous cells and multiple procedures. However, clinical translation remains a challenge. Gene therapy strategies being developed are reviewed by Evans [2] and include direct injection of vectors into sites of injury, use of genetically modified allogeneic cell lines and the intraoperative harvest of autologous tissues that are quickly transduced and returned to the body. Recently, in silico models for enhanced understanding and optimization of cells, carriers, culture and clinics have been developed for better integration of in silico tools into clinical practice [3].

The use of bone marrow-derived mesenchymal stem cells (BM-MSCs) due to low yields and significant in vitro culture expansion has financial implications. Also, harvesting of bone marrow cells is paralleled with associated morbidity. The development of bone tissue engineering is directly related to progress in materials technology. While the inclusion of materials requirements is standard in the design of engineered bone substitutes, the potentials of BM-MSCs in trauma and orthopaedics presents the clinical need for bone tissueengineered alternatives.

The use of induced pluripotent stem cells (iPSCs) in bone regenerative strategies has been advanced to present for the first time in this issue a novel direct-plating method with a clinically relevant approach for generating large numbers of 
homogenous iPSC-derived osteoprogenitor cells for bone repair [4]. The cells have a high osteogenic differentiation capacity, indicating that this novel method provides a clinically applicable and simple procedure for generating a large number of homogenous iPSC-derived osteoprogenitor cells for bone healing.

The use of BM-MSCs for joint and bone diseases is presented by Marmotti et al. [5], with particular reference to characterization of stem cell site of residence, differentiation potential and therapeutic prospective. Their potential use in bone, cartilage and meniscus is discussed. Bone cell therapy following skeletal injuries requiring bone augmentation has emerged as a promising technique to augment and promote bone regeneration [6]. To initiate clinical trials using bone cells, appropriate preclinical studies with clearly defined end-points are required [7]. In this respect, harmonization procedures between the European Medicines Agency and national regulatory agencies are under consideration with regard to several projects funded by the European Commission, including REBORNE and OSTEOGROW.

The efficiency of the biologic augmentation of the rotator cuff repair using iliac BM-MSCs has been evaluated in 45 patients by Hernigou et al. [8]. A significant improvement in healing outcomes has been achieved, supporting the use of MSC augmentation and a reduced number of re-tears observed in MSC treated patients.

Among other cells with a potential to regenerate organs the application of pericytes for mesenchymal tissue engineering is an expanding field of interest elaborated by Mravic et al. [9].

An increased risk for tumour local recurrence following removal of malignant primary bone tumours has been investigated in patients treated with BM-MSCs, and the local cancer recurrence was not increased following autologous cell therapy in the follow-up period of more than ten years [10].

Osteonecrosis of the femoral head is one unsolved medical problem for which an appropriate preclinical model has not been available. However, in a paper by Poignard et al. [11] a novel pig model is presented and seems to be relevant for clinical trials.

Open tibial fractures are associated with a high proportion of bone non-unions and the use of bone marrow autologous concentrate has been tested in 43 patients suggesting that this technique is effective, harmless and cost affordable [12]. In a retrospective study of 523 patients with bone marrow aspiration and 435 with classical iliac crest bone graft procedure, the number of complications at the harvesting site was ten times lower than complications observed with the classical approach [13].

The extra-cellular environment is complex with a wide range of physical features, topographies and protein compositions. Two-dimensional (2D) substrates have been widely used to study the effect of material properties on cell migration. However, such substrates do not capture the intricate structure of the extra-cellular environment. Recent advances in hydrogel assembly and patterning techniques have enabled the design of new three-dimensional (3D) scaffolds and microenvironments. This growing field of research will have significant impact on tissue engineering, regenerative medicine and in the design of biomaterials. The most promising hydrogels for articular cartilage, osteochondral and bone defects in combination with inductive signals and cell sources are reviewed by Moreire et al. [14].

Nano-materials have a significant impact in tissue engineering. The types of nano-structured scaffolds and nanoparticle delivery systems for bone regeneration are discussed by Ivkovic et al. [15].

The level of angiogenic cytokines in synovial fluid and plasma of patients with osteoarthritis (OA) and healthy volunteers has been explored by Mabey et al. [16] to suggest that folistatin, angiopoietin-2, and VEGF may have a potential as biochemical markers for assessing the OA severity. In addition, cytokines and chemokines involved in activation of osteoclast progenitors have been analyzed in patients with psoriatic arthritis by Sucur et al. [17] to identify crucial bone/joint chemotactic mediators as promising therapeutic targets in arthritis.

Articular cartilage has an extraordinary biomechanical performance and simple structure. However, it is vulnerable to multifactorial damage and insufficient to self-repair, isolated in the articular capsule without nerves or blood vessels. Restoration of hyaline cartilage in $\mathrm{OA}$ is a clinical challenge to recreate normal functionality over a long period. Pre-clinical trials have achieved promising outcomes in cartilage regeneration using MSCs. The rationale and technologies of MSC-based hyaline cartilage repair involving tissue engineering, 3D biomaterials and growth factors is elaborated in translation and application of MSC-based chondrogenesis for OA treatment. In the articular cartilage repair process, it is imperative to consider the type of biologic and the method of delivery to achieve the desired effect in cartilage repair. A number of spatiotemporal strategies will be discussed for the controlled delivery of bioactive factors in cartilage tissue engineering applications. Focal chondral and osteochondral knee lesions are common conditions which are hard to treat when involving young active patients with high expectations of symptoms relief. Autologous osteochondral transplantation has been performed in 31 men and women affected by such lesions and followed for 24 months. Filardo et al. [18] reported that the clinical improvement is slow and patients develop symptoms attributable to the donor area, thus reducing the overall benefit of the procedure.

The use of bone allografts for reinforcing major osteolytic bone lesions of the acetabulum at revision total hip arthroplasty has been elaborated in 60 patients treated with or without an additional graft enrichment with BM-MSCs. 
Results indicate a significantly lower rate of acetabular defect failures in patients with the BM-MSCs enriched allograft procedure [19].

To combine gene therapy and cell transplantation approaches to enhance meniscal repair nonviral gene transfer systems have been tested in human juvenile and adults meniscal fibro-chondrocytes to suggest a safe and effective procedure for maintaining the expression of selected transgenes [20]. In addition, 3D alginate spheres have been tested for culturing human meniscal fibro-chondrocytes transfected with expression plasmid vectors carrying the Photinus pyralis luciferase gene, the Escherichia coli $\beta$ galactosidase gene or a human FGF-2 cDNA. Results support a cell-based approach for meniscal repair using meniscal fibro-chondrocytes overexpressing FGF-2 [21].

Recently, scaffolds consisting of natural polymers, such as collagen and gelatin, bioabsorbable synthetic polymers, such as polylactic and polyglycolic acid, and inorganic materials, such as hydroxyapatite, as well as composite materials have been developed.

The efficacy of meniscal replacement therapy has been tested in biopsies of patients priorly treated with implanted allografts or synthetic scaffolds. Moran et al. [22] suggest that both viable allograft and a polyurethane meniscal scaffold show enhanced regenerative patterns over the deep frozen allograft following surgical implantation. Due to limitations of viable allograft availability development of synthetic meniscal scaffolds is a promising option.

Collagen is the most promising material for tissue engineering due to its biocompatibility, biodegradability and specific cell adhesion domains, including the arginine-glycine-aspartic acid (RGD) motif. Following the integrin receptor on the cell surface binding to the RGD motif on the collagen molecule, cell adhesion is actively induced. Grassi et al. [23] review clinical outcomes in patients treated with collagen meniscus implant (CMI) and suggest an improvement in knee function and pain with a low rate of reoperations.

BM-MSCs have been further tested in an experimental model of osteogenesis imperfecta in mice. Cells delivered locally to femurs of mice differentiate into osteoblasts and osteocytes and maintain their progenitor potential in vivo, suggesting that local delivery of autologous MSCs in which osteogenesis imperfecta mutations have been corrected is a promising therapeutic approach for patients with this deleterious bone phenotype [24].

The demineralized bone matrix (DBM) has been used to originally isolate and characterize bone morphogenetic proteins (BMPs) [25-29]. However, due to osteoinductive potential of DBM several preparations from human bone are still in clinical use. Fassbender et al. [30] compare two different clinically used DBMs to conclude that they are not capable of reconstructing critical size defects in a rat model.
The use of induced membranes for critical bone limb defects are reviewed by Auregan et al. [31] who suggest that this technique is important for facilitating bone inclusion of new bone substitutes in recent bioengineering procedures.

To test whether the potential systemic bioavailability following a local bone administration of BMP2 and BMP7 might affect the skeletal metabolism, Dumic-Cule et al. [32] systemically administered BMP2 and -7 in animals lacking calciotropic hormones and in this issue report that both BMPs increase the bone volume. These results suggest that BMP2 and -7 released from commercially used bone devices do not mediate a systemic bone loss in previously treated patients.

Das et al. [33] explored the use of BMP7 in improving bone healing in 20 patients with congenital pseudoarthrosis of the tibia and found that at the five-year follow up BMP7 and autograft were equally effective to autograft alone, although there was a trend to primary bone union in patients treated with BMP7. Manrique et al. [34] compared the biomechanical properties of tricalcium phosphate, tricalcium phosphate with BMP7 and autologous bone marrow aspirate with BMP7 of vertebral lesions in a porcine model and found that tricalcium phosphate with BMP7 generate major resistance of vertebrae to an external energy.

Flouzat Lachaniette et al. [35] explored the bone fusion rates following use of anterior lumbar interbody fusion in 51 patients treated with autologous iliac crest bone graft and BMP2 using thin-cut CT scan images at one-year follow up. Authors report that BMP2 is inferior to the autologous bone graft regarding the rate and quality of bone fusion.

This special issue composed of non-clinical and clinical reports including systemic reviews on specific musculoskeletal topics should support further progress in developing new strategies and therapies for skeletal tissues, specifically for the aged population in need.

\section{References}

1. Pecina M, Vukicevic S (2007) Biological aspects of bone, cartilage and tendon regeneration. Int Orthop 31:719-720. doi:10.1007/ s00264-007-0425-7

2. Evans $\mathrm{CH}$ (2014) Using genes to facilitate the endogenous repair and regeneration of orthopaedic tissue. Int Orthop. doi:10.1007/s00264014-2423-x

3. Geris L (2014) Regenerative orthopaedics: in vitro, in vivo ...in silico. Int Orthop. doi:10.1007/s00264-014-24196-6

4. Dogaki Y, Lee S, Niikura T, Iwakura T, Okumachi E, Waki T, Kakutani K, Nishida K, Kuroda R, Kurosaka M (2014) Efficient derivation of osteoprogenitor cells from mouse induced pluripotent stem cells for bone regeneration. Int Orthop. doi:10.1007/s00264014-2440-9

5. Marmotti A, de Girolamo L, Bonasia DE, Bruzzone M, Mattia S, Rossi R, Montaruli A, Detonni F, Castoldi F, Peretti G (2014) Stem cells in joint and bone diseases: a concise review. Int Orthop. doi:10. 1007/s00264-014-2445-4 
6. Barrena-Gomez E, Avendano-Sola C, Bunu C (2014) Regulatory authorities and orthopaedic clinical trials on expanded mesenchymal stem cells. Int Orthop. doi:10.1007/s00264-014-2332-z

7. Peric M, Dumic-Cule I, Grcevic D, Matijasic M, Verbanac D, Grgurevic L, Trkulja V, Bagi C, Vukicevic S (2014) The rational use of animal models in the evaluation of novel bone regenerative therapies. Bone. doi:10.1016/j.bone.2014.07.010

8. Hernigou P, Flouzat Lachaniette CH, Delambre J, Zilber S, Duffiet P, Chevallier N (2014) Biologic augmentation of rotator cuff repair with mesenchymal stem cells during arthroscopy improves healing and prevents re-tears: a case controlled study. Int Orthop. doi:10.1007/ s00264-014-2391-1

9. Mravic M, Asatrian G, Soo C, Lugassy C, Barnhill RL, Dry SM, Peault B, James AW (2014) From pericytes to perivascular tumours: correlation between pathology, stem cell biology, and tissue engineering. Int Orthop. doi:10.1007/s00264-014-2295-0

10. Hernigou P, Flouzat Lachaniette CH, Delambre J, Chevallier N, Rouard H (2014) Regenerative therapy with mesenchymal stem cells at the site of malignant primary bone tumour resection: what are the risks of early or late local recurrence? Int Orthop. doi:10.1007/ s00264-014-2384-0

11. Poignard A, Lebouvier A, Cavet M, Rahmouni A, Flouzat Lachaniette $\mathrm{CH}$, Bierling $\mathrm{P}$, Rouard $\mathrm{H}$, Hernigou P, Chevallier $\mathrm{N}$ (2014) New preclinical porcine model of femoral head osteonecrosis to test mesenchymal stromal cell efficiency in regenerative medicine. Int Orthop. doi:10.1007/s00264-014-2352-8

12. Le Nail LR, Stanovici J, Fournier J, Splingard M, Domenech J, Rosset P (2014) Percutaneous grafting with bone marrow autologous concentrate for open tibia fractures: analysis of forty three cases and literature review. Int Orthop. doi:10.1007/s00264-014-2342-x

13. Hernigou P, Desroches A, Queinnec S, Flouzat Lachaniette $\mathrm{CH}$, Poignard A, Allain J, Chevallier N, Rouard H (2014) Morbidity of graft harvesting versus bone marrow aspiration in cell regenerative therapy. Int Orthop. doi:10.1007/s00264-014-2318-x

14. Moreira Teixeira LS, Patterson J, Luyten FP (2014) Skeletal tissue regeneration: where can hydrogels play a role? Int Orthop. doi:10. 1007/s00264-014-2402-2

15. Gusic N, Ivkovic A, VaFaye J, Vukasovic A, Ivkovic J, Hudetz D, Jankovic S (2014) Nanobiotechnology and bone regeneration: a mini-review. Int Orthop. doi:10.1007/s00264-014-2412-0

16. Mabey T, Honsawek S, Saetan N, Poovorawan Y, Tanavalee A, Yuktanandana P (2014) Angiogenic cytokine expression profiles in plasma and synovial fluid of primary knee osteoarthritis. Int Orthop. doi:10.1007/s00264-014-2406-y

17. Sucur A, Katavic V, Kelava T, Jajic Z, Kovacic N, Grcevic D (2014) Induction of osteoclast progenitors in inflammatory conditions: key to bone destruction in arthritis. Int Orthop. doi:10.1007/s00264-0142386-y

18. Filardo G, Kon E, Perdisa F, Balboni F, Marcacci M (2014) Autologous osteochondral transplantation for the treatment of knee lesions: results and limitations at two years' follow-up. Int Orthop. doi:10.1007/s00264-014-2322-1

19. Hernigou P, Pariat J, Queinnec S, Homma Y, Lachaniette $\mathrm{CH}$, Chevallier N, Rouard H (2014) Supercharging irradiated allografts with mesenchymal stem cells improves acetabular bone grafting in revision arthroplasty. Int Orthop. doi:10.1007/s00264-014-2285-2

20. Lee HP, Kaul G, Cucchiarini M, Madry H (2014) Nonviral gene transfer to human meniscal cells. Part I: transfection analyses and cell transplantation to meniscus explants. Int Orthop. doi:10.1007/ s00264-014-2410-2

21. Lee HP, Rey-Rico A, Cucchiarini M, Madry H (2014) Nonviral gene transfer into human meniscal cells. Part II: effect of three-dimensional environment and overexpression of human fibroblast growth factor 2 . Int Orthop. doi:10.1007/s00264-014-2405-Z

22. Moran CJ, Atmaca S, Declercq HA, Cornelissen MJ, Verdonk PC (2014) Cell distribution and regenerative activity following meniscus replacement. Int Orthop. doi:10.1007/s00264-014-2426-7

23. Grassi A, Zaffagnini S, Marcheggiani Muccioli GM, Benzi A, Marcacci M (2014) Clinical outcomes and complications of a collagen meniscus implant: a systematic review. Int Orthop. doi:10.1007/ s00264-014-2408-9

24. Pauley P, Matthews BG, Wang L, Dyment NA, Matic I, Rowe DW, Kalajzic I (2014) Local transplantation is an effective method for cell delivery in the osteogenesis imperfecta murine model. Int Orthop. doi:10.1007/s00264-013-2249-y

25. Urist MR (1965) Bone: formation by autoinduction. Science 150: 893-899

26. Reddi AH, Huggins C (1972) Biochemical sequences in the transformation of normal fibroblasts in adolescent rats. Proc Natl Acad Sci USA 69:1601-1605

27. Wozney JM, Rosen V, Celeste AJ, Mitsock LM, Whitters MJ, Kriz RW, Hewick RM, Wang EA (1988) Novel regulators of bone formation: molecular clones and activities. Science 242:1528-1534

28. Luyten FP, Cunningham NS, Ma S, Muthukumaran N, Hammonds RG, Nevins WB, Woods WI, Reddi AH (1989) Purification and partial amino acid sequence of osteogenin, a protein initiating bone differentiation. J Biol Chem 264:13377-13380

29. Vukicevic S, Sampath TK (2002) Bone morphogenetic proteins: From laboratory to clinical practice. Birkhauser Verlag, BaselBoston-Berlin

30. Fassbender M, Minkwitz S, Thiele M, Wildemann B (2014) Efficacy of two different demineralised bone matrix grafts to promote bone healing in a critical-size-defect: a radiological, histological and histomorphometric study in rat femurs. Int Orthop. doi:10.1007/ s00264-014-2321-2

31. Auregan JC, Begue T (2014) Induced membrane for treatment of critical sized bone defect: a review of experimental and clinical experiences. Int Orthop. doi:10.1007/s00264-014-2422-y

32. Dumic-Cule I, Brkljacic J, Rogic D, Bordukalo-Niksic T, Tikvica Luetic A, Draca N, Kufner V, Trkulja V, Grgurevic L, Vukicevic S (2014) Systemically available bone morphogenetic protein 2 and 7 affect bone metabolism. Int Orthop. doi:10.1007/s00264-014-2425-8

33. Das SP, Shankar G, Pradhan S, Singh D, Mohanty RN (2014) Effectiveness of recombinant human bone morphogenetic protein-7 in the management of congenital pseudoarthrosis of the tibia: a randomised controlled trial. Int Orthop. doi:10.1007/s00264-0142361-7

34. Manrique E, Chaparro D, Cebrian JL, Lopez-Duran L (2014) In vivo tricalcium phosphate, bone morphogenetic protein and autologous bone marrow biomechanical enhancement in vertebral fractures in a porcine model. Int Orthop. doi:10.1007/s00264-014-2377-z

35. Flouzat-Lachaniette $\mathrm{CH}$, Ghazanfari A, Bouthors C, Poignard A, Hernigou P, Allain J (2014) Bone union rate with recombinant human bone morphogenic protein-2 versus autologous iliac bone in PEEK cages for anterior lumbar interbody fusion. Int Orthop. doi:10.1007/ s00264-014-2301-6 